\title{
Video Article \\ Biotinylated Cell-penetrating Peptides to Study Intracellular Protein-protein Interactions
}

\author{
Myriam Jaraíz-Rodríguez ${ }^{1}$, Ana González-Sánchez ${ }^{1,2}$, Laura García-Vicente ${ }^{1}$, Jose M. Medina ${ }^{1}$, Arantxa Tabernero ${ }^{1}$ \\ ${ }^{1}$ Instituto de Neurociencias de Castilla y León (INCYL), Departamento de Bioquímica y Biología Molecular, Universidad de Salamanca \\ ${ }^{2}$ Centre for Cancer Research \& Cell Biology (CCRCB), School of Medicine, Dentistry and Biomedical Sciences, Queen's University Belfast
}

Correspondence to: Arantxa Tabernero at ataber@usal.es

URL: https://www.jove.com/video/56457

DOI: doi: $10.3791 / 56457$

Keywords: Biochemistry, Issue 130, TAT, Biotin-avidin, Cell-penetrating peptides, Pull-down, Intracellular interactions, Protein-protein interactions, Western blot

Date Published: $12 / 20 / 2017$

Citation: Jaraíz-Rodríguez, M., González-Sánchez, A., García-Vicente, L., Medina, J.M., Tabernero, A. Biotinylated Cell-penetrating Peptides to Study Intracellular Protein-protein Interactions. J. Vis. Exp. (130), e56457, doi:10.3791/56457 (2017).

\section{Abstract}

Here we present a protocol to study intracellular protein-protein interactions that is based on the widely used biotin-avidin pull-down system. The modification presented includes the combination of this technique with cell-penetrating sequences. We propose to design cell-penetrating baits that can be incubated with living cells instead of cell lysates and therefore the interactions found will reflect those that occur within the intracellular context. Connexin43 (Cx43), a protein that forms gap junction channels and hemichannels is down-regulated in high-grade gliomas. The Cx43 region comprising amino acids $266-283$ is responsible for the inhibition of the oncogenic activity of c-Src in glioma cells. Here we use TAT as the cell-penetrating sequence, biotin as the pull-down tag and the region of Cx43 comprised between amino acids $266-283$ as the target to find intracellular interactions in the hard-to-transfect human glioma stem cells. One of the limitations of the proposed method is that the molecule used as bait could fail to fold properly and, consequently, the interactions found could not be associated with the effect. However, this method can be especially interesting for the interactions involved in signal transduction pathways because they are usually carried out by intrinsically disordered regions and, therefore, they do not require an ordered folding. In addition, one of the advantages of the proposed method is that the relevance of each residue on the interaction can be easily studied. This is a modular system; therefore, other cell-penetrating sequences, other tags, and other intracellular targets can be employed. Finally, the scope of this protocol is far beyond protein-protein interaction because this system can be applied to other bioactive cargoes such as RNA sequences, nanoparticles, viruses or any molecule that can be transduced with cell-penetrating sequences and fused to pull-down tags to study their intracellular mechanism of action.

\section{Video Link}

The video component of this article can be found at https://www.jove.com/video/56457/

\section{Introduction}

Protein-protein interactions are essential for a great variety of cellular processes. To fully understand these processes, methods for identifying protein interactions within the complex intracellular environment are required. One of the most used methods to identify interaction partners of a protein is to use that protein or a mimetic peptide of a part of that protein as bait in affinity pull-down experiments followed by detection of binding proteins. The avidin-biotin system is frequently used because of the high affinity, specificity and stable interaction between avidin and biotin ${ }^{1,2}$. Usually, biotin is covalently bound to the bait (protein or peptide) and after a period of incubation with the cell lysates to allow the establishment of interactions, the biotinylated bait bound to its intracellular partners is pulled down with avidin or avidin derivatives conjugated with support beads. Then, bait-protein interactions are detected after washing, elution, and analysis by denaturing electrophoresis followed by Western blot. One of the problems of this technique is that the interactions between the protein of interest and its intracellular partners are taking place outside of the cellular context. This is especially important for the interactions involved in signal transduction pathways because they take place in specific intracellular locations, they are transient and they are typically carried out by not abundant proteins. Therefore, within the cell lysates these interactions can be masked by other more abundant proteins or by proteins that usually are not in close proximity.

Cell-penetrating peptides (CPPs) are short peptides ( $\leq 40$ amino acids), composed mostly by cationic amino acids that are capable of transporting a wide range of molecules into almost any cell ${ }^{3}$. Cargoes such as proteins, plasmid DNA, siRNA, viruses, imaging agents, and various nanoparticles have been conjugated to CPPs and efficiently internalized ${ }^{4,5}$. Because of this transporting ability they are also known as protein transduction domains (PTDs), membrane translocating sequences (MTSs), and Trojan peptides. Among the CPPs, the TAT peptide from the HIV transactivator protein TAT ${ }^{6}$ has been one of the most widely studied ${ }^{7,8,9}$. TAT is a nonapeptide that contains 6 arginine and 2 lysine residues and consequently is highly cationic. Substitution studies have demonstrated that the net positive charge of TAT is necessary for electrostatic interactions with the plasma membranes of eukaryotic cells and its subsequent internalization ${ }^{10}$. Similarly to other CPPs, positivelycharged TAT strongly binds electrostatically to the various negatively-charged species present at the extracellular surface of cell membranes, including lipid head groups, glycoproteins and proteoglycans ${ }^{3,10}$. The bioactive cargoes transported by TAT become immediately free in the cytosol to reach their intracellular partners. 
Here we present a method that combines the TAT CPP with biotin to study intracellular interactions. The aim is to design cell-penetrating baits by fusing the target biomolecule to TAT and to biotin. The main advantage of this proposal is that the interactions between the bait and its partners will take place within its cellular context. To show the efficacy of this method we used as bait a small sequence of the protein Cx43 that has been reported to interact intracellularly with the proto-oncogene $\mathrm{c}-\mathrm{Src}^{11,12,13}$. Cx43 is an integral membrane protein that is widely expressed in astrocytes ${ }^{14}$ and is down-regulated in high-grade gliomas, the most common malignant tumor of the central nervous system ${ }^{15,16,17,18}$.It has been previously shown that the Cx43 region that interacts with c-Src (amino acids 266-283 in human Cx43; Pubmed: P17302) fused to TAT (TAT-Cx43 $266-283$ ) inhibits the oncogenic activity of c-Srcin glioma cells and glioma stem cells (GSCs) ${ }^{19,20,21}$. To design the intracellular bait, $\mathrm{C} \times 43_{266-283}$ has been fused to TAT at the $\mathrm{N}$-terminus (TAT-Cx43 $266-283$ ) and to biotin at the C-terminus (TAT-Cx43266-283-B). This strategy has been successfully used in the rat glioma C6 cell line to identify c-Src, c-terminal Src kinase (CSK) and phosphatase and tensin homolog (PTEN) as intracellular partners of this region of $\mathrm{Cx} 43^{20}$. Here, we describe this method testing its efficacy in human GSCs, which are very relevant for glioma therapy but much harder to transfect than non-stem glioma cells.

\section{Protocol}

All experimental procedures were carried out at the University of Salamanca.

\section{Cells}

1. Two days before starting the procedure, plate the cells at the required density to be confluent the day of the experiment. Plate the cells in flasks or plates. However, the protein extraction will be easier from plates. It is convenient to prepare at least 4 plates of $78 \mathrm{~cm}^{2}$ or $2 \mathrm{flasks}$ of $150 \mathrm{~cm}^{2}$ per condition per experiment, to be sure that the results are consistent.

2. In this study, plate human G166 GSCs in 4 flasks of $150 \mathrm{~cm}^{2}$, cultured in RHB-A stem cell medium supplemented with $2 \%$ B27, $1 \%$ N2, 20 $\mathrm{ng} / \mathrm{mL}$ EGF and b-FGF as described by Pollard et al. ${ }^{22}$. Process when confluence was reached. For instance, when $5 \times 10^{6} \mathrm{G} 166$ cells were plated in a $150 \mathrm{~cm}^{2}$ flask, they were processed 2 days after plating.

\section{Biotinylated CPPs}

1. Spin the vials containing the lyophilized biotinylated CPPs (BCPPs) at $8200 \times g$ for $30 \mathrm{~s}$, to avoid some of the powder remaining on the lid. Include a control BCPP to be sure that the interactions found are specific of the target sequence. In this study, the control BCPP was TATbiotin (TAT-B) and the treatment BCPP was TAT-Cx43 $266-283-\mathrm{B}$. Other controls could be used, such as TAT fused to scrambled or mutated fragments bond to biotin.

2. Dissolve the BCPPs in the corresponding culture medium to the stock solution indicated by the manufacturer; for instance, to obtain a stock solution of $2 \mathrm{mg} / \mathrm{mL}$ BCPP to treat GSCs add $0.5 \mathrm{~mL}$ of GSC culture medium to one vial containing $1 \mathrm{mg}$ of the BCPP. Vortex and make sure the peptide is well dissolved.

\section{Tubes}

NOTE: Prepare at least twelve $1.5 \mathrm{~mL}$ tubes per condition required in the Section 7.

1. Mark the first 3 tubes per condition. They will have the total volume of cellular lysates obtained in step 6.4.

2. Mark an A in 3 tubes per condition. These tubes will have the first supernatants obtained after lysing and spinning the cellular lysates, step 7.2 .

3. Mark a B in 3 tubes per condition. These tubes will have a small aliquot of the first supernatants. These lysates will serve as the Western blot samples in step 7.3.

4. Mark a C in 3 tubes per condition. These tubes will have the supernatants obtained after the pull-down with NeutrAvidin, step 7.7. NOTE: This is important in case the Western blot showed no signal for proteins, meaning the proteins were not pulled down or were lost at some step of the procedure. If this were the situation, repeat the process to pull down the proteins.

\section{Cellular treatment with the BCPPs}

1. Aspirate the culture medium.

2. Replace the corresponding volume of fresh medium required to incubate the BCPPs in the smallest possible volume of medium according to the incubation times. It is very important that in any case, the medium covers completely the whole surface of the plate/flask so that the cells do not dry out, for instance, $6 \mathrm{~mL}$ per $150 \mathrm{~cm}^{2}$ for a 30 min incubation.

3. Add the volume of the stock solution of BCPP to the cell cultures to reach the concentration that has been proved to be effective. In this study $50 \mu \mathrm{M}$ TAT-C $\times \mathbf{4 3}_{266-283}-\mathrm{B}$ has been proved to reduce GSC proliferation.

1. Therefore, add $92.8 \mu \mathrm{L}$ of $2 \mathrm{mg} / \mathrm{mL}$ TAT-Cx43 $266-283-\mathrm{B}(\mathrm{MW}=3723.34 \mathrm{~g} / \mathrm{mol})$ per $\mathrm{mL}$ of culture medium to obtain a final concentration of $50 \mu \mathrm{M}$ TAT-Cx $43_{266-283}$-B. If the volume to be added is different for control peptides, complete with culture medium up to the same final volume. For instance, $49.1 \mu \mathrm{L}$ TAT-B (MW=1914.31 $\mathrm{g} / \mathrm{mol})$ plus $43.7 \mu \mathrm{L} \mathrm{GSC}$ medium were added per mL of culture medium to obtain a final concentration of $50 \mu \mathrm{M}$ TAT-B.

4. Place the cells in the incubator at $37^{\circ} \mathrm{C}$ and $5 \% \mathrm{CO}_{2}$ for $30 \mathrm{~min}$ to make sure that the interactions between the $\mathrm{BCPP}$ and its intracellular partners take place. If the interaction takes longer, incubate for longer times or adjust times in case the experiment consisted of a timecourse. In addition, the interaction of interest can be promoted or prevented by stimulating different intracellular signaling pathways. 


\section{Buffers and solutions.}

1. Prepare PBS pH 7.4: $136 \mathrm{mM} \mathrm{NaCl} ; 2.7 \mathrm{mM} \mathrm{KCl} ; 7.8 \mathrm{mM} \mathrm{Na}_{2} \mathrm{HPO}_{4} \cdot 2 \mathrm{H}_{2} \mathrm{O} ; 1.7 \mathrm{mM} \mathrm{KH}_{2} \mathrm{PO}_{4}$.

2. Prepare protein lysis buffer: $20 \mathrm{mM}$ Tris- $\mathrm{HCl}(\mathrm{pH} 8.0), 137 \mathrm{mM} \mathrm{NaCl}, 1 \%$ IGEPAL, Prior to use, add the following: $1 / 100$ ( $/ \mathrm{v}$ ) Protease Inhibitor Cocktail, $1 \mathrm{mM}$ Sodium Fluoride, $1 \mathrm{mM}$ Phenylmethanesulfonyl fluoride (PMSF) and $0.1 \mathrm{mM}$ Sodium orthovanadate.

3. Prepare Laemmli buffer: (4x: $0.18 \mathrm{M}$ Tris-HCl pH 6.8; $5 \mathrm{M}$ glycerol; $3.7 \%$ SDS (p/v); $0.6 \mathrm{M} \beta$-mercaptoethanol or $9 \mathrm{mM}$ DTT; $0.04 \%$ ( $/ \mathrm{v}$ ) bromophenol blue (BB)).

\section{Protein extraction}

NOTE: Protein extraction was performed as previously described ${ }^{20,23}$. Carry out this whole section of the procedure at $4{ }^{\circ} \mathrm{C}$.

1. Aspirate the culture medium completely.

2. Wash $3 \times 10 \mathrm{~mL}$ of with ice-cold phosphate buffered saline (PBS) per $150 \mathrm{~cm}^{2}$ very carefully to avoid cell detachment.

3. To obtain the cell lysate, add $3 \mathrm{~mL}$ of lysis buffer per $150 \mathrm{~cm}^{2}$ and thoroughly scrape the surface by using a cell scraper. Tilting the plate/flask to about 45 degrees will make easier to gather the cell lysates into their corresponding tubes.

4. Pour $1 \mathrm{~mL}$ of the cellular lysate per tube in three $1.5 \mathrm{~mL}$ tubes. These tubes will be marked with the condition and the replicate as indicated in step 3.1.

\section{Pull-down}

1. Centrifuge the $1.5 \mathrm{~mL}$ tubes at $11,000 \times \mathrm{g}$ for $10 \mathrm{~min}$ at $4{ }^{\circ} \mathrm{C}$.

2. Transfer the supernatants to new tubes (A).

3. Take an aliquot of this supernatant per condition to different tubes (B), i.e. $50 \mu \mathrm{L}$ per tube. Add $4 x$ Laemmli buffer (16.6 $\mu \mathrm{L}$ for $50 \mu \mathrm{L}$ of lysate) and freeze at $-20^{\circ} \mathrm{C}$. These lysates will serve as usual Western blot samples.

4. Homogenize very well the NeutrAvidin Agarose by gentle shaking. Cut the tips of the pipette tips to increase their diameter and improve the pipetting of the beads. Add $50 \mu \mathrm{L}$ of NeutrAvidin Agarose per $\mathrm{mL}$ of cell lysate in the $(\mathrm{A})$ tubes.

5. Incubate at $4{ }^{\circ} \mathrm{C}$ overnight with very gentle shaking to allow NeutrAvidin to interact with BCPPs bound to their intracellular partners.

6. Centrifuge at $3,000 \times g$ for $1 \mathrm{~min}$ at $4{ }^{\circ} \mathrm{C}$ to collect the complex of NeutrAvidin with proteins.

7. Carefully remove the supernatants and transfer them to clean tubes (C). Keep them to use them in case the pull-down is not successful.

8. Washing steps: add fresh lysis buffer to the pellets (tubes A), resuspend by inversion and repeat the steps 7.6) and 7.7) for 5 more times. All these supernatants can be discarded.

9. Remove the supernatants and add $2 x$ Laemmli buffer to the desired final volume $\left(40 \mu \mathrm{L}\right.$ per $1.5 \mathrm{~mL}$ tube for pellets obtained from $150 \mathrm{~cm}^{2}$ flasks of confluent cells).

10. Elute at $100{ }^{\circ} \mathrm{C}$ for $5 \mathrm{~min}$ to dissociate the interactions between proteins and centrifuge for $30 \mathrm{~s}$ at $8,200 \times g$ to pellet NeutrAvidin beads.

11. Take the supernatants, containing the dissociated proteins, with capillary tips to new tubes (D). The beads can be kept in case repeating elution steps is required.

NOTE: The supernatants (tubes $\mathrm{D}$ ) are now ready to be loaded in Western blot or to freeze at $-20{ }^{\circ} \mathrm{C}$.

\section{Western Blot}

NOTE: Western blotting was performed as previously described ${ }^{24}$.

1. Load equivalent volume of each sample per lane on Bis-Tris (4-12\%) midigels in a Midi-Cell Electrophoresis System.

2. Transblot proteins using a dry blotting system into a nitrocellulose regular stack.

3. Stain the membrane with $10 \%$ Ponceau for $10 \mathrm{~min}$.

4. Wash the membranes $3 \times 5$ min with $5 \mathrm{~mL}$ of TTBS.

5. Block the membranes with $7 \%$ milk in TTBS for $1 \mathrm{~h}$ with gentle shaking in tubes or small boxes. Make sure the volume used is enough to cover the membranes and that they do not dry, i.e. $40 \mathrm{~mL}$ per whole midi membrane.

6. Wash $3 \times 5$ min with $5 \mathrm{~mL}$ of TTBS.

7. Incubate overnight at $4{ }^{\circ} \mathrm{C}$ with the primary antibody against the protein of interest with gentle shaking.

8. Wash $3 \times 5$ min with $5 \mathrm{~mL}$ of TTBS.

9. Incubate the membrane at room temperature with the correspondent peroxidase-conjugated secondary antibody in TTBS for $1 \mathrm{~h}$.

10. Wash $3 \times 5$ min with $5 \mathrm{~mL}$ of TTBS.

11. Develop with a chemiluminescent substrate in a chemiluminescence system.

\section{Problem Solving}

1. If after developing the Western blot any of the samples showed no signal at all for proteins, check the Ponceau. NOTE: The membrane in Ponceau should show undefined and numerous bands along the lanes loaded. If the bands are not very noticeable, the quantity of proteins loaded may not be enough or the transference may have gone incorrectly. Consider repeating the Western blot.

2. If there is no stain at all in the Ponceau membrane in any lane, repeat the whole procedure from the step 7.4 in the (C) tubes.

3. If after developing the Western blot a protein signal is very weak but the Ponceau showed proteins, incubate again the membrane with the primary antibody for longer time. If the signal is still rather weak, incubate again at room temperature. 


\section{Other Techniques Used in this Article}

\section{Immunocytochemistry of BCPPs}

1. Fix cells in $4 \%$ paraformaldehyde $\left(0.2 \mathrm{~mL}^{2}\right.$ per $\left.\mathrm{cm}^{2}\right)$ for $20 \mathrm{~min}$.

2. Wash $3 \times 5 \mathrm{~min}$ with PBS $\left(0.2 \mathrm{~mL}\right.$ per $\left.\mathrm{cm}^{2}\right)$.

3. Apply the corresponding antibody (at least $0.15 \mathrm{~mL}$ per $\mathrm{cm}^{2}$ ) diluted in antibody solution at the manufacturer's indicated concentration against your protein of interest overnight at $4{ }^{\circ} \mathrm{C}$.

4. Incubate with a fluorophore-conjugated secondary antibody $\left(0.15 \mathrm{~mL}\right.$ per $\left.\mathrm{cm}^{2}\right)$ for $2 \mathrm{~h}$ at room temperature.

5. Repeat steps 10.1.2-10.1.4 with other antibodies against your proteins of interest. Be careful not to use the same species for different primary antibodies or same wavelength fluorophores for secondary antibodies.

6. Mount the cells using the antifade reagent $\left(0.005 \mathrm{~mL}\right.$ per $\left.\mathrm{cm}^{2}\right)$.

7. Analyze on a fluorescence microscope connected to a digital camera.

\section{MTT assay}

1. Culture the cells at $37^{\circ} \mathrm{C}$ in 24 -well plates.

2. Incubate the cells in the dark for $75 \mathrm{~min}$ with $0.15 \mathrm{~mL}$ of culture medium per $\mathrm{cm}^{2}$ containing $0.5 \mathrm{mg} / \mathrm{mL}$ MTT.

3. Aspirate the medium and incubate the cells for $10 \mathrm{~min}$ in the dark with dimethyl sulfoxide $\left(0.25 \mathrm{~mL}\right.$ per $\left.\mathrm{cm}^{2}\right)$ with mild shaking.

4. Measure the absorbance at a wavelength of $570 \mathrm{~nm}$ using a microplate reader.

\section{Representative Results}

Before using BCPPs to study intracellular interaction, it is critical to compare the effects of BCPP vs CPP to validate the results obtained with BCPP. Consequently, to study whether the inclusion of biotin modifies the activity of the target sequence, we first analyzed the effect of TATCx43 $266-283$-B compared with TAT-Cx $43_{266-283}$ on G166 GSCs morphology. To do so, we performed some immunofluorescence analyses of two cytoskeletal proteins, F-actin and $\alpha$-tubulin after $24 \mathrm{~h}$ of treatment. Figure 1 shows that G166 GSCs in the presence of $50 \mu \mathrm{M}$ TAT-Cx43 $266-283$ or TAT-C $\times 43_{266-283}-\mathrm{B}$ acquire a more rounded shape compared to the elongated and expanded cellular prolongations shown in the controls (TAT or TAT-B). In fact, Figure 1b shows that actin filaments are mostly assembled as actin networks when the cells were treated with TAT$\mathrm{C} \times 43_{266-283}$ or TAT-C $\times 43_{266-283}-\mathrm{B}$ while they form more actin bundles in the control cells (treated with TAT or TAT-B) ${ }^{25}$. In contrast, $\alpha$-tubulin distribution does not vary between the different conditions. These results showed that the presence of biotin did not modify the effect of the target sequence on the morphology of G166 GSCs. In previous studies ${ }^{20,21}$, we showed that TAT-Cx43 ${ }_{266-283}$ reduced G166 GSCs proliferation. In this study, we investigated whether TAT-Cx43 $266-283$-B exerts the same effects in the growth as TAT-Cx43 $266-283$. To do so, we analyzed the G166 GSCs proliferation by MTT assay after $72 \mathrm{~h}$ of treatment. The MTT assay is a colorimetric assay for assessing cell metabolic activity. MTT is metabolized by NAD $(P) H$ oxidoreductase enzymes in mitochondria reflecting the number of viable cells present. Figure 2 shows that the reduction in the G166 GSCs cell viability is not significantly different when cells were treated with $50 \mu \mathrm{M}$ TAT-Cx43 $266-283$ or $50 \mu \mathrm{M}$ TATCx43266-283-B. Indeed, both significantly diminished G166 GSCs proliferation as compared to the control, TAT or TAT-B.

Once we confirmed that the effect of our target sequence in G166 GSCs (TAT-Cx43 $266-283$ ) was not modified by the inclusion of biotin at the Cterminus (TAT-Cx43 $266-283-B$ ), we investigated the intracellular partners of this sequence following the protocol described in this study (Figure 3). Because caveolae have been involved in the mechanism of TAT internalization ${ }^{26}$, we analyzed the presence of caveolin-1 (Cav-1) in the pulldowns. Western blot analysis (Figure 4) showed that TAT-B and TAT-Cx43 $266-283^{-B}$ interact with Cav-1. However, the ability of TAT-Cx43 $266-283^{-}$ $B$ to recruit c-Src, PTEN and CSK is stronger than that found with TAT-B. Focal adhesion kinase (FAK) is a substrate of c-Src that has not been shown to interact with $\mathrm{Cx} 43$. Indeed, FAK did not show any significant interaction with either TAT-B or TAT-Cx43 $266-283-\mathrm{B}$.

To confirm the interaction between TAT-Cx43 $266-283^{-B}$ and c-Src, G166 GSCs were incubated with $50 \mu \mathrm{M}$ TAT-Cx43 $266-283-\mathrm{B}$ for 30 min and their localization was followed with fluorescent streptavidin by confocal microscopy (Figure 5). Our results showed that the intracellular distribution of TAT-Cx43 $266-283^{-B}$ is close to the plasma membrane (shown by phosphatidylserine staining) and matches with that of c-Src. In fact, colocalization analyses revealed some points of co-localization (white) between TAT-Cx43 $266-283$-B and c-Src in the merge image. Consequently, confocal microscopy studies confirm the results obtained with the BCPP pull-down protocol described in this study. 
a)

a) $\quad$-actin
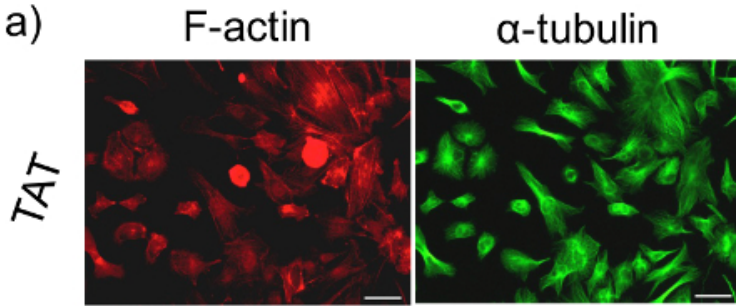

merge

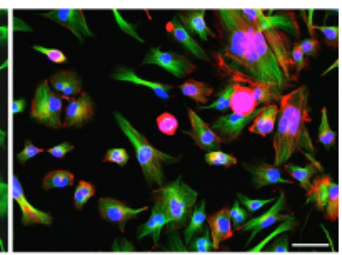

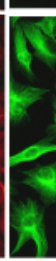
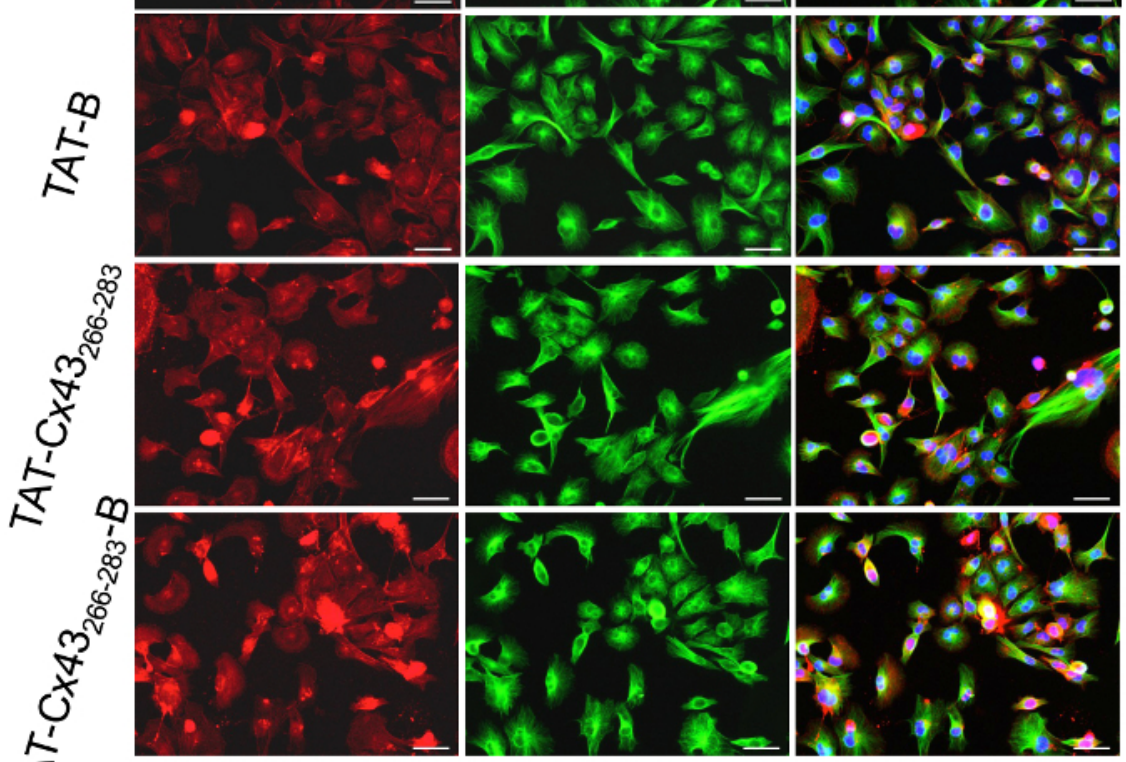

b)

\section{F-actin}

Figure 1: Effect of BCPP and CPP on GSC morphology.

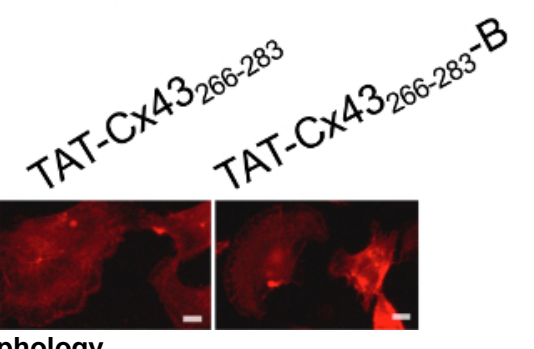

G166 GSCs were plated at a low density $\left(2 \times 10^{4}\right.$ cells $\left./ \mathrm{cm}^{2}\right)$ and after $24 \mathrm{~h}$ they were incubated with $50 \mu \mathrm{M}$ control CPP (TAT), control BCPP (TAT-B), treatment CPP (TAT-Cx43 $266-283$ ) or treatment BCPP (TAT-Cx43 $266-283$-B). a) F-actin (red), $\alpha$-tubulin (green) and merged + DAPI immunostaining of the same field showing G166 GSCs morphology. Bars $=50 \mu \mathrm{m}$. b) F-actin immunostaining showing the different distribution of F-actin in G166 GSCs after incubation for $24 \mathrm{~h}$ with $50 \mu \mathrm{M}$ control CPP (TAT) or control BCPP (TAT-B) as compared with $50 \mu \mathrm{M}$ treatment CPP $\left(\right.$ TAT-Cx43 $266-283$ ) or BCPP $\left(\right.$ TAT-C $\left.x 43_{266-283}-\mathrm{B}\right)$. Bars $=10 \mu \mathrm{m}$. Please click here to view a larger version of this figure. 


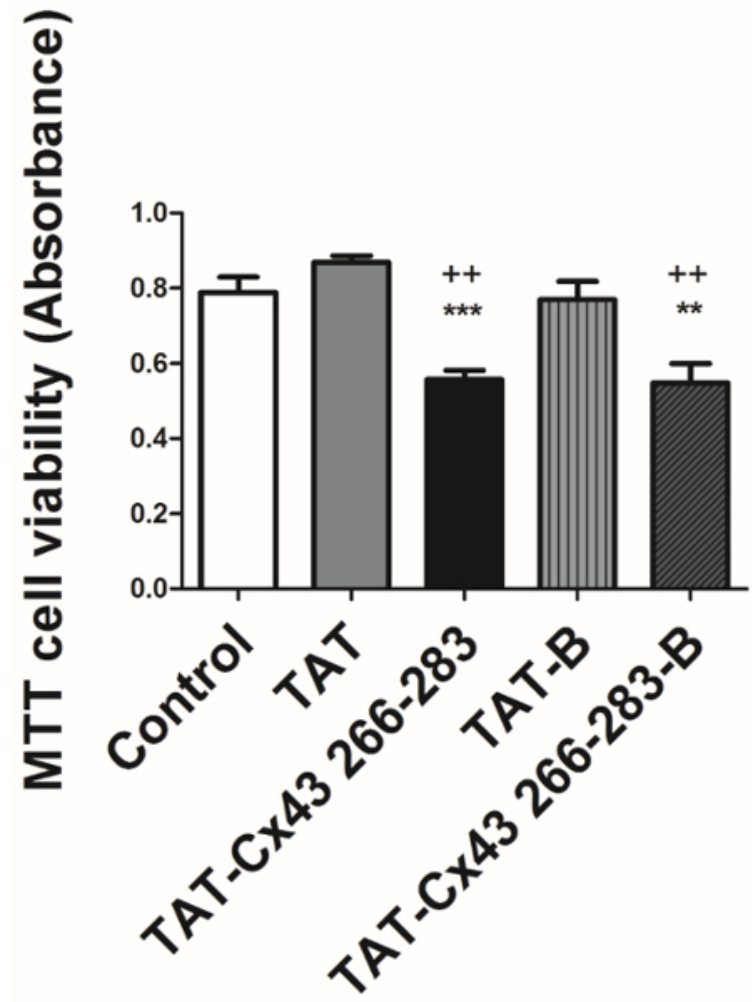

Figure 2: Effect of BCPP and CPP on GSC viability.

G166 GSCs were plated at 5500 cells $/ \mathrm{cm}^{2}$ in 24-multiwell plates and incubated with $50 \mu \mathrm{M}$ control peptides, CPP (TAT) or BCPP (TAT-B), or 50 $\mu \mathrm{M}$ treatment peptides, CPP (TAT-Cx43 $266-283$ ) or BCPP (TAT-Cx43 $266-283-\mathrm{B})$. The cell viability was analyzed using a MTT assay after $72 \mathrm{~h}$. The results are expressed as MTT absorbances and are the mean \pm s.e.m. of at least 3 experiments $\left(++p<0.01\right.$ vs control. ${ }^{* *} p<0.01$, ${ }^{* * *} p<0.001$ vs TAT or TAT-B; one-way ANOVA withTukey post-test). Note that there are not significant differences between the effects of CPPs vs BCPPs. Please click here to view a larger version of this figure. 

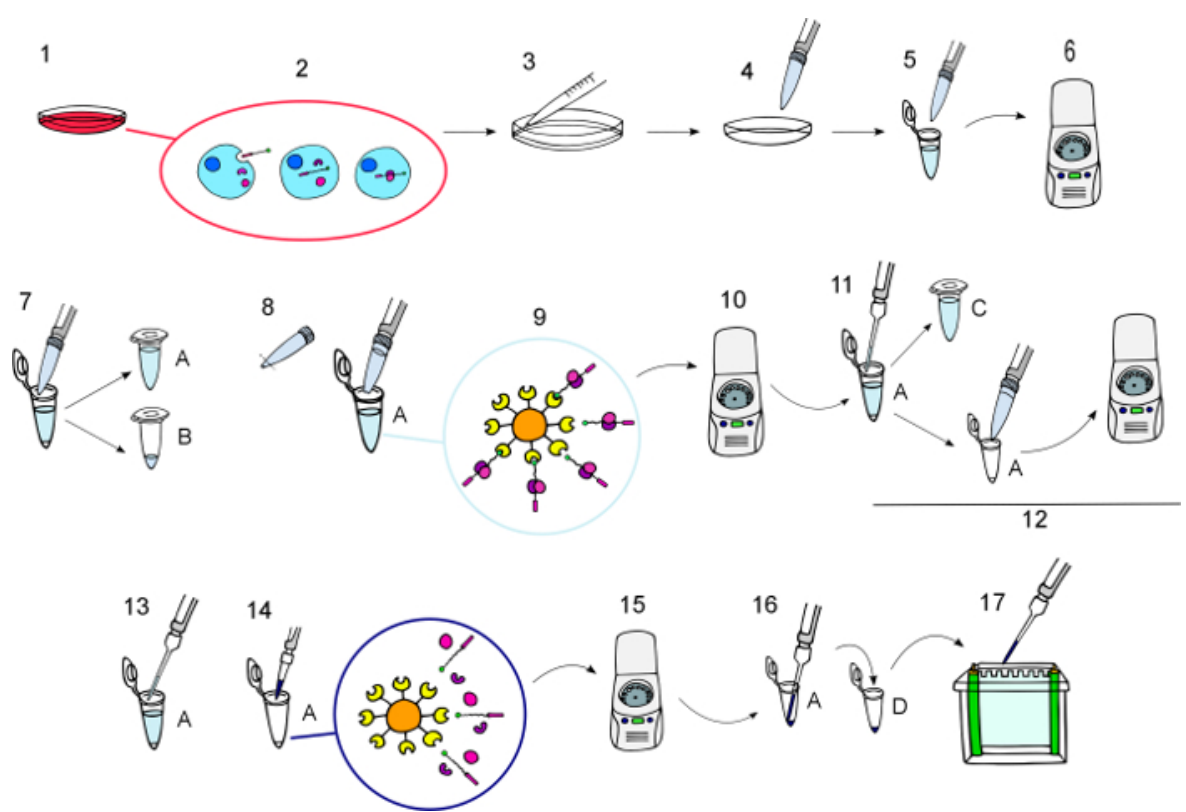

Figure 3: Protocol diagram.

Step by step graphical depiction of the procedure as described in the section "Protocol", from the incubation of the BCPPs until the eluted BCPPs and their interacting proteins were obtained.1) Incubate culture cells with BCPPs at the desired concentration for the required time. 2) During the incubation, the BCPPs are internalized and they interact with their intracellular partners. 3) Wash the cells three times on ice with ice-cold PBS. 4) Lyse the cells to extract proteins. 5) Transfer cell lysates to tubes. 6) Spin at $11000 \times g$ for 10 min at $4{ }^{\circ} \mathrm{C}$. 7) Transfer the supernatants to new tubes (A) and keep a small aliquot of the lysates to process as regular Western blot samples in tube (B). 8) Resuspend the NeutrAvidin Agarose beads and add $50 \mu \mathrm{L}$ to each tube A using a cut pipette tip. 9) Incubate with gently shaking for $12 \mathrm{~h}$ at $4{ }^{\circ} \mathrm{C}$ to allow the NeutrAvidin agarose beads to interact with BCPPs and their partners. 10) Spin for $1 \mathrm{~min}$ at $3000 \mathrm{xg}$ to pellet the beads with the biotinylated baits and their interacting proteins bound to them. 11) Transfer supernatants to new tubes (C) and keep them to use in case the pull-down need to be repeated. 12) Wash the pellet five times with fresh lysis buffer, resuspend by inversion, spin for $1 \mathrm{~min}$ at $3000 \times g$ and discard the supernatant. 13) Remove all the supernatant carefully. 14) Add the desired volume of $4 x$ Laemmli buffer and elute the proteins at $100{ }^{\circ} \mathrm{C}$ for $5 \mathrm{~min}$. 15) Spin at $8200 \times \mathrm{g}$ for $30 \mathrm{~s}$ to pellet the beads. 16) Transfer the eluted proteins found in the supernatant with capillary tips to new tubes (D). 17) Load onto gels for Western blot analysis. Please click here to view a larger version of this figure. 
$\mathrm{kDa}$
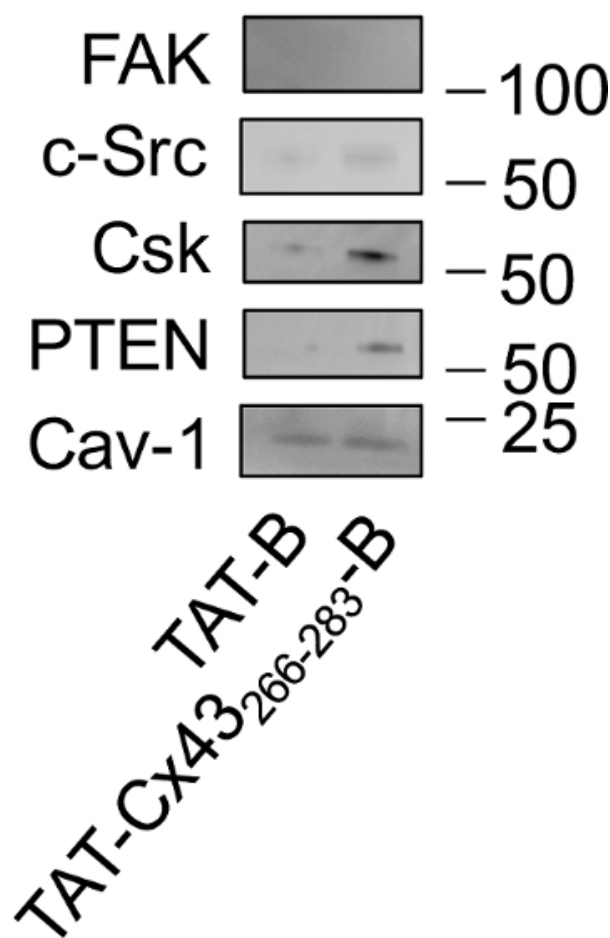

Figure 4: Study of the intracellular interactions of TAT-Cx43 $266-283$-B in G166 GSCs by pull-down followed by Western blot.

G166 GSCs were incubated with $50 \mu \mathrm{M}$ TAT-B or TAT-Cx43 $366-283^{-B}$. After 30 min the cells were lysed and TAT-B or TAT-Cx43 $266-283^{-B}$ attached to their intracellular partners were pulled down with NeutrAvidin beads. The eluted proteins were loaded and analyzed by Western blot to study the levels of FAK, c-Src, CSK, PTEN and Cav-1. Note that Cav-1 interacts with both TAT-B and TAT-Cx43 $266-283^{-B}, \mathrm{C}-\mathrm{Src}, \mathrm{PTEN}$ and CSK interact preferentially with TAT-C $\times 43_{266-283}-\mathrm{B}$ and FAK did not show any interaction with either TAT-B or TAT-Cx43 $266-283-\mathrm{B}$. Please click here to view a larger version of this figure. 


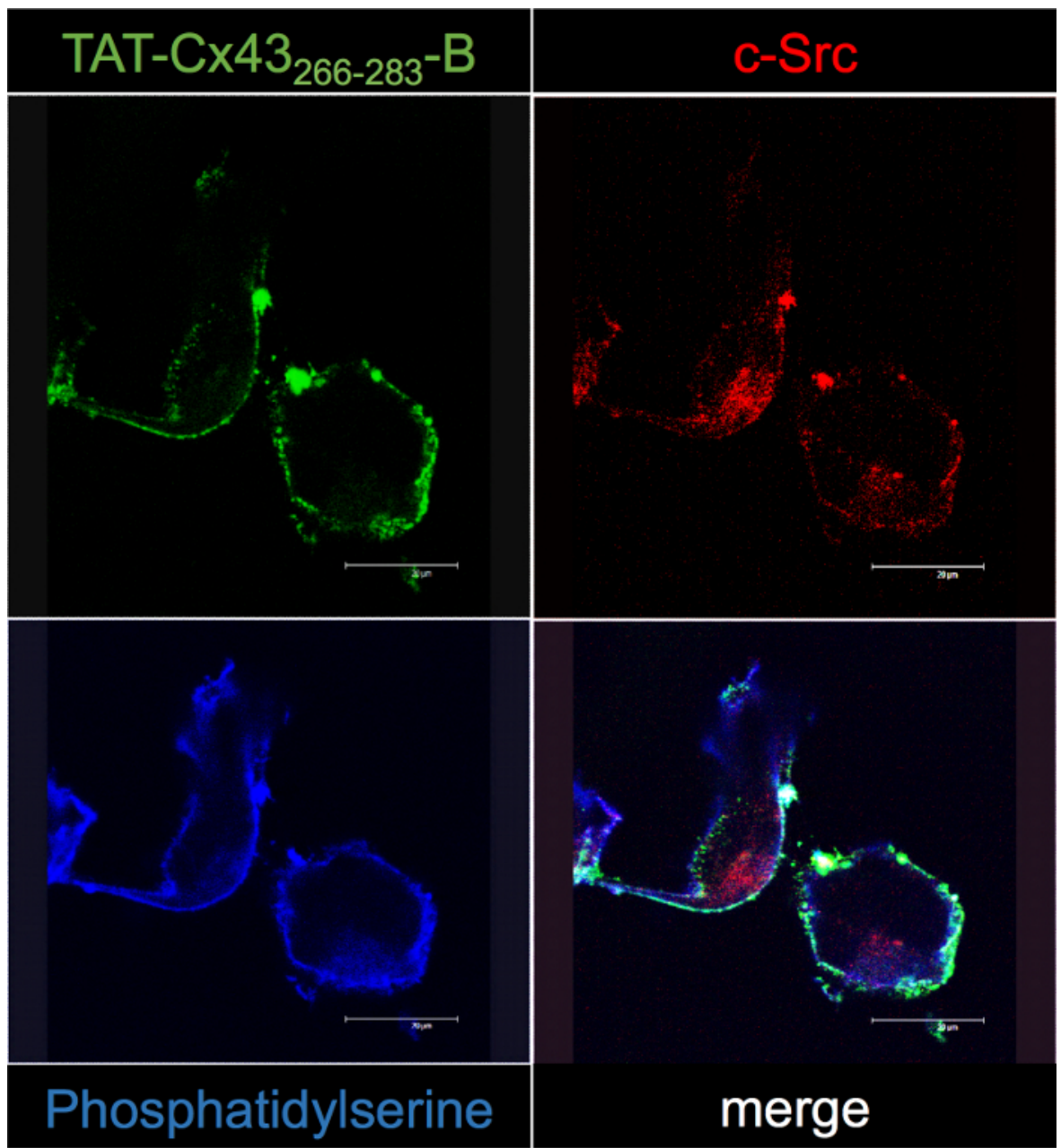

Figure 5: Confirmation of TAT-Cx43 $266-283-B$ intracellular interactions in $\mathbf{G 1 6 6}$ GSCs by confocal microscopy.

G166 GSCs were incubated with $50 \mu \mathrm{M}$ TAT-Cx43 $266-283-B$. After 30 min, cells were fixed and processed to localize TAT-Cx43 $266-283-B$ with Cy2Streptavidin (green), c-Src by immunofluorescence (red) and phosphatidylserine with annexin V (blue). Note some points of co-localization (white) between TAT-Cx43 $266-283-\mathrm{B}$ and c-Src close to the plasma membrane in the merge images. Please click here to view a larger version of this figure.

\section{Discussion}

There are many methods to study protein-protein interactions. The method presented in this study is based on the widely used biotin-avidin pulldown system in which a biotinylated bait is incubated with cell lysates to allow the establishment of interactions. The modification presented in this study includes the combination of this technique with cell-penetrating sequences. We propose to design cell-penetrating baits that can be incubated with living cells instead of cell lysates and therefore the interactions found will reflect those that occurred within the cellular context.

Here we use TAT as the cell-penetrating sequence, biotin as the pull-down tag and the region of Cx43 comprised between amino acids $266-283$ as the target to find intracellular interactions in human GSCs. The structural basis for the interaction between Cx43 and c-Src is well known ${ }^{11,12}$. This is an important interaction because it inhibits the oncogenic activity of c-Src in glioma cells ${ }^{24,13}$. In fact, CPPs containing this region (TAT$\mathrm{Cx}_{4} 3_{266-283}$ ) mimic the antioncogenic properties of Cx43 on glioma cells ${ }^{19,20,21}$. In rat glioma C6 cells, the mechanism by which TAT-Cx43 $266-283$ inhibits c-Src includes the recruitment of c-Src together with its endogenous inhibitors CSK and PTEN ${ }^{20}$. It should be mentioned that GSCs are very interesting as a target in glioma therapy, because they constitute a subpopulation that is resistant to conventional treatments and therefore responsible for the recurrence of this malignant brain tumors ${ }^{27}$. Furthermore, they are hard-to-transfect cells and therefore the study of intracellular interactions becomes more difficult. CPPs are rapidly and efficiently internalized in GSCs ${ }^{19}$ favoring their use for the study of intracellular interactions. In this study, using CPPs fused to biotin we confirm the interaction of the $\mathrm{Cx}_{43} 3_{266-283}$ sequence with c-Src together with its endogenous inhibitors CSK and PTEN in human GSCs.

This method is very powerful to study the intracellular mechanism of bioactive compounds. However, it is very important to confirm that the biological effect of the biotinylated cell penetrating bait is not different from that obtained with the non-biotinylated one. This step is required to associate the interactions found with the effect of the bioactive compound. In addition, the stability of the compound, its possible degradation by proteases as well as its possible toxicity, should be carefully tested and taken into account before planning the experiment. In the example presented, the anti-proliferative effect of TAT-Cx43 $266-283$ on G166 human GSCs has been previously documented ${ }^{20}$. In this study, we confirm that the anti-proliferative effect of TAT-Cx $43_{266-283}-\mathrm{B}$ and of TAT-Cx $43_{266-283}$ is very similar. In addition, the analysis of cellular morphology revealed that $\alpha$-tubulin and F-actin distribution is very similar in G166 GSCs treated with TAT-Cx43 $266-283-\mathrm{B}$ or with TAT-Cx43 $266-283$. Altogether, 
these results indicate that the inclusion of biotin at the c-terminus of TAT-Cx $43_{266-283}$ did not modify the effects of this compound on human GSCs. However, if biotin would modify the effects of the bioactive molecule, other tags for protein purification can be tested, such as the FLAG octapeptide (DYKDDDDK) ${ }^{28}$, the human influenza hemagglutinin-derived tag HA (YPYDVPDYA) or glutathione S-transferase (GST) ${ }^{29}$. Similarly, if TAT does not target the cell population of interest, other cell penetrating sequences, such as penetratin, MPG (for a review, see ${ }^{30}$ ) or cell specific sequences can be used ${ }^{31}$.

In addition to study proteins that specifically interact with the target sequence, ideally, the presence of proteins that interact with both the control and the target sequence and proteins that do not interact with them, as positive and negative controls, should be addressed. In this sense, we found Cav-1 in the control and treated situation, suggesting that the caveolae have been involved in the mechanism of internalization, as it has been previously shown ${ }^{26}$. Furthermore, FAK, which interacts with c-Src but is supposed not to interact with the Cx43 c-terminal, was absent in both the control and treated situation. These results reinforce the specificity of the interaction between TAT-Cx $43_{266-283}-\mathrm{B}$, c-Src, CSK and PTEN.To confirm the results obtained with this protocol, confocal microscopy can be used to visualize the distribution of the interacting proteins and to study their co-localization. Thus, we found that TAT-Cx $43_{266-283}-\mathrm{B}$ and c-Src exhibit a similar intracellular distribution with some points of co-localization confirming the results obtained with the pull-down experiments. In fact, TAT-Cx43 $266-283-\mathrm{B}$ is distributed close to the plasma membrane suggesting that the cargo, in this study $\mathrm{C} \times 43_{266-283}$, directs the molecule to its intracellular partners.

One of the limitations of the proposed method is that the molecule used as bait could fail to fold properly and the expected effects would not be found. In this situation, the interactions found could not be associated to the effect. However, this method can be especially interesting for the interactions involved in signal transduction pathways because they are usually carried out by intrinsically disordered regions ${ }^{32}$ and therefore they do not require an ordered folding. In addition, one of the advantages of the proposed method is that the time course of the interaction can be followed, which is especially relevant for transient interactions. Furthermore, the relevance of each residue on the interaction can be easily studied. Indeed, it is possible to study the relevance of posttranslational modifications on protein-protein interaction, for instance, by phosphomimetic substitution of glutamate for serine or threonine. Similarly, substitution of serine or threonine for alanine or tyrosine for phenylalanine allows testing the effect of non-phosphorylatable serine, threonine or tyrosine. To mimic phospho-tyrosine, the most accurate way is the substitution of Tyr for $\mathrm{p}-\mathrm{Tyr}^{33}$.

Finally, the scope of this protocol is far beyond protein-protein interaction because this system can be applied to other bioactive cargoes such as RNA sequences, nanoparticles, viruses or other molecules that can be fused to biotin and transduced with CPP to study their intracellular mechanism of action.

\section{Disclosures}

The authors have nothing to disclose.

\section{Acknowledgements}

We thank M. Morales and J. Bravo for their help with the design of CPPs and J.C. Arévalo for his help with the pull-down protocol. We are grateful for the technical assistance of T. del Rey. This work was supported by the Ministerio de Economía y Competitividad, Spain; FEDER BFU2015-70040-R, Junta de Castilla y León, Spain; FEDER SA026U16 and Fundación Ramón Areces. M. Jaraíz-Rodríguez and A. GonzálezSánchez are recipients of a fellowship from the Junta de Castilla y León and the European Social Fund.

\section{References}

1. Green, N.M. Avidin. 3. The nature of the biotin-binding site. Biochem J. 89, 599-609 (1963).

2. Wilchek, M., \& Bayer, E.A. Applications of avidin-biotin technology: literature survey. Methods Enzymol. 184, 14-45 (1990).

3. Herce, H.D., Garcia, A.E., \& Cardoso, M.C. Fundamental molecular mechanism for the cellular uptake of guanidinium-rich molecules. $J$ Am Chem Soc. 136 (50), 17459-17467 (2014).

4. Ramsey, J.D., \& Flynn, N.H. Cell-penetrating peptides transport therapeutics into cells. Pharmacol Ther. 154, 78-86 (2015).

5. Fominaya, J., Bravo, J., \& Rebollo, A. Strategies to stabilize cell penetrating peptides for in vivo applications. Ther Deliv. 6 (10), 1171-1194 (2015).

6. Vives, E., Brodin, P., \& Lebleu, B. A truncated HIV-1 Tat protein basic domain rapidly translocates through the plasma membrane and accumulates in the cell nucleus. J Biol Chem. 272 (25), 16010-16017 (1997).

7. Gump, J.M., \& Dowdy, S.F. TAT transduction: the molecular mechanism and therapeutic prospects. Trends Mol Med. 13 (10), $443-448$ (2007).

8. Brooks, H., Lebleu, B., \& Vives, E. Tat peptide-mediated cellular delivery: back to basics. Adv Drug Deliv Rev. 57 (4), $559-577$ (2005).

9. Cuesto, G. et al. Phosphoinositide-3-kinase activation controls synaptogenesis and spinogenesis in hippocampal neurons. $J$ Neurosci. 31 (8), 2721-2733 (2011).

10. Schmidt, N., Mishra, A., Lai, G.H., \& Wong, G.C. Arginine-rich cell-penetrating peptides. FEBS Lett. 584 (9), $1806-1813$ (2010).

11. Sorgen, P.L. et al. Structural changes in the carboxyl terminus of the gap junction protein connexin 43 indicates signaling between binding domains for c-Src and zonula occludens-1. J Biol Chem. 279 (52), 54695-54701 (2004).

12. Giepmans, B.N., Hengeveld, T., Postma, F.R., \& Moolenaar, W.H. Interaction of C-Src with gap junction protein connexin-43. Role in the regulation of cell-cell communication. J Biol Chem. 276 (11), 8544-8549 (2001).

13. Tabernero, A., Gangoso, E., Jaraíz-Rodríguez, M., \& Medina, J.M. The role of connexin43-Src interaction in astrocytomas: A molecular puzzle. Neuroscience. 323, 183-194 (2016).

14. Giaume, C., Koulakoff, A., Roux, L., Holcman, D., \& Rouach, N. Astroglial networks: a step further in neuroglial and gliovascular interactions. Nat Rev Neurosci. 11 (2), 87-99 (2010).

15. Shinoura, N. et al. Protein and messenger RNA expression of connexin43 in astrocytomas: implications in brain tumor gene therapy. $J$ Neurosurg. 84, 839-845 (1996). 
16. Soroceanu, L., Manning, T., \& Sontheimer, H. Reduced expression of connexin-43 and functional gap junction coupling in human gliomas. Glia. 33, 107-117 (2001).

17. Pu, P., Xia, Z., Yu, S., \& Huang, Q. Altered expression of Cx43 in astrocytic tumors. Clin Neurol Neurosurg. 107 (1), $49-54$ (2004)

18. Crespin, S. et al. Expression of a gap junction protein, connexin43, in a large panel of human gliomas: new insights. Cancer Med. 5 (8), 1742-1752 (2016).

19. Gangoso, E., Thirant, C., Chneiweiss, H., Medina, J.M., \& Tabernero, A. A cell-penetrating peptide based on the interaction between c-Src and connexin43 reverses glioma stem cell phenotype. Cell Death \& Disease. 5 (2014).

20. Gonzalez-Sanchez, A. et al. Connexin43 recruits PTEN and Csk to inhibit c-Src activity in glioma cells and astrocytes. Oncotarget. 7 (31), 49819-49833 (2016).

21. Jaraíz-Rodríguez, M. et al. A short region of connexin43 reduces human glioma stem cell migration, invasion and survival through Src, PTEN and FAK. Stem Cell Reports. 9 (2), 451-463 (2017).

22. Pollard, S.M. et al. Glioma stem cell lines expanded in adherent culture have tumor-specific phenotypes and are suitable for chemical and genetic screens. Cell Stem Cell. 4 (6), 568-580 (2009).

23. $\mathrm{Yu}, \mathrm{T}$. et al. In vivo regulation of NGF-mediated functions by Nedd4-2 ubiquitination of TrkA. $J$ Neurosci. 34 (17), 6098-6106 (2014).

24. Herrero-Gonzalez, S. et al. Connexin43 inhibits the oncogenic activity of c-Src in C6 glioma cells. Oncogene. 29 (42), $5712-5723$ (2010).

25. Cooper, G.M. In: The Cell: A Molecular Approach. 2nd edition., Sinauer Associates (2000).

26. Fittipaldi, A. et al. Cell membrane lipid rafts mediate caveolar endocytosis of HIV-1 Tat fusion proteins. J Biol Chem. 278 (36), 34141-34149 (2003).

27. Dirks, P.B. Brain tumor stem cells: the cancer stem cell hypothesis writ large. Mol Oncol. 4 (5), $420-430$ (2010).

28. Hopp, T.P. et al. A Short Polypeptide Marker Sequence Useful for Recombinant Protein Identification and Purification. Nat Biotech. 6 (10), 1204-1210 (1988).

29. Benard, V., \& Bokoch, G.M. Assay of Cdc42, Rac, and Rho GTPase activation by affinity methods. Methods Enzymol. 345, 349-359 (2002).

30. Guidotti, G., Brambilla, L., \& Rossi, D. Cell-Penetrating Peptides: From Basic Research to Clinics. Trends Pharmacol Sci. 38 (4), $406-424$ (2017).

31. Hu, Q. et al. Glioma therapy using tumor homing and penetrating peptide-functionalized PEG-PLA nanoparticles loaded with paclitaxel. Biomaterials. 34 (22), 5640-5650 (2013).

32. Babu, M.M., van der Lee, R., de Groot, N.S., \& Gsponer, J. Intrinsically disordered proteins: regulation and disease. Curr Opin Struct Biol. 21 (3), 432-440 (2011).

33. Anthis, N.J. et al. Beta integrin tyrosine phosphorylation is a conserved mechanism for regulating talin-induced integrin activation. $J$ Biol Chem. 284 (52), 36700-36710 (2009). 